\title{
ANALISIS KUALITAS DAN PENGEMBANGAN SISTEM INFORMASI AKADEMIK BERBASIS WEB MENGGUNAKAN STANDARD ISO 9126
}

\author{
Tika Novita Sari \\ Universitas Gadjah Mada \\ e-mail: tikansari@gmail.com
}

\begin{abstract}
ABSTRAK
Penelitian ini bertujuan untuk merancang dan membuat sistem informasi akademik SMK Negeri 2 Depok Sleman berbasis web serta mengetahui kualitas perangkat lunak yang dikembangkan berdasarkan ISO 9126. Penelitian ini menggunakan metode Research and Development $(R \& D)$ dan model pengembangan Waterfall. Model pengembangan waterfall yaitu analisis kebutuhan, desain, implementasi, dan pengujian. Pengujian perangkat lunak dilakukan berdasarkan Web Quality Evaluation Method (WebQEM), dengan aspek: functionality, efficiency, reliability, dan usability. Hasil dari penelitian ini adalah:(1) Sistem Informasi Akademik SMK Negeri 2 Depok Sleman dikembangkan menggunakan framework Codeigniter dengan fitur: manajemen admin, manajemen guru, manajemen wali kelas, dan siswa (rapor); dan (2) hasil pengujian sistem informasi akademik diperoleh nilai functionality sebesar 1 (Baik), pengujian efficiency diperoleh nilai $96 \%$ dengan YSlow dan 94\% dengan Page Speed (Grade A) dan waktu respon sebesar 3,33 detik (Diterima), pengujian reliability diperoleh tingkat reliability 99,5\% (Memenuhi), dan pengujian usability sebesar 74,33\% (Tinggi) dan nilai Apha-Cronbach 0,872 (Baik). Berdasarkan hasil analis kualitas dengan WebQEM tersebut maka sistem informasi akademik yang dikembangkan layak untuk digunakan.
\end{abstract}

Kata kunci: Kualitas Perangkat Lunak, Sistem Informasi Akademik, Web, ISO 9126, WebQEM

\begin{abstract}
The aims of the research are being able to design and develop web-based academic information system of SMKN 2 Depok, and knowing the quality of the software developed based on ISO 9126. The methods of this research are Research and Development $(R \& D)$ and Waterfall development model, these are need analysis, design, implementation (coding); and testing. Testing of software is done based on Web Quality Evaluation Method (WebQEM), these aspect are: functionality, efficiency, reliability, and usability. The results of this research are: (1) Academic information system of SMK Negeri 2 Depok Sleman developed using Codeigniter framework supported by features: admin management, teacher management, and student (report); and (2) the value of functionality is 1 (Good), 96\% for efficiency test using YSlow and 94\% by PageSpeed (Grade A) and load time is 3,33 second (Accepted), reliability test is 99,5\% (Appropriate), and usability test is 74,33\% (High) followed by 0,872 for Alpha-Cronbach (Good).
\end{abstract}

Keywords: Software Quality, Academic Information System, Web, ISO 9126

\section{PENDAhUluan}

$\mathrm{M}$ utu sebuah sekolah dapat dilihat dari tertibnya administrasi dan pelayanan. Salah satu bentuk tertib administrasi adalah adanya mekanisme kerja yang efektif dan efisien, baik secara vertikal maupun horizontal [1]. Menurut [2], salah satu ciri-ciri sekolah yang bermutu adalah berfokus pada pelanggan, baik pelanggan internal maupun eksternal. Ciri-ciri mutu sekolah lainnya adalah nilai moral tinggi, hasil ujian tinggi, penerapan teknologi terbaru, pemimpin yang kuat, perhatian terhadap siswa, serta dukungan orang tua dan masyarakat.

Peneliti telah melakukan survey di SMK Negeri 2 Depok Sleman yaitu dengan narasumber Bapak Sugiarto, S.T., pada tanggal 20 November 2013 yang merupakan staff ahli wakil kepala sekolah bidang kurikulum. Saat ini SMK Negeri 2 Depok Sleman sedang meningkatkan pelayanan administrasi sekolah. Sarana dan prasarana di sekolah ini cukup lengkap, salah satunya adalah fasilitas internet. Namun, dalam menyampaikan informasi kepada guru, siswa, wali kelas, karyawan, maupun wali murid sekolah ini masih menggunakan media lisan dan tulisan (kertas). Kendala yang dihadapi dengan cara tersebut adalah harus menyiapkan koordinasi antara guru dan wali kelas sehingga memerlukan waktu lama. Informasi yang cepat berubah membuat sekolah ini harus berulangulang mengadakan koordinasi dan perubahan informasi.

Proses pengelolaan nilai akademik di SMK Negeri 2 Depok Sleman dapat dikatakan cukup rumit. Pertama, guru pengampu mengolah nilai siswa yang diampunya kemudian diserahkan kepada bagian kurikulum. Selanjutnya bagian kurikulum menyerahkan berkas tersebut kepada wali kelas. Wali kelas memasukkan nilai dalam rapor, dan menyerahkan kembali kepada bagian kurikulum. Proses tersebut rumit dan membutuhkan waktu lama. 
Berdasarkan permasalahan tersebut, maka diperlukan sebuah sistem informasi untuk mengelola nilai akademik siswa yang diuji kualitasnya. Sistem yang diusulkan diuji dengan standar ISO 9126 yang telah diidentifikasi oleh [3] dalam WebQEM meliputi functionality, efficiency, reliability, dan usability. ISO 9126 dipilih karena merupakan standar kualitas internasional yang sudah teruji validitas dan reliabilitasnya.

Tujuan dari penelitian ini adalah mengetahui proses perancangan dan pembuatan perangkat lunak sistem informasi akademik dan mengetahui kualitas perangkat lunak yang dikembangkan berdasarkan standar ISO 9126. Sistem ini diharapkan dapat bermanfaat untuk pengguna yaitu guru dan siswa serta peneliti untuk memahami lebih jauh tentang teknologi informasi.

\section{A. ISO 9126}

\section{METODE}

International Organization for Standarization (ISO) dalam ISO Standard 9126 telah mengusulkan beberapa karakteristik untuk melakukan pengujian terhadap kualitas sebuah perangkat lunak. ISO-9126 [4] mengidentifikasikan enam karakteristik sebuah perangkat lunak dikatakan berkualitas yaitu: functionality, reliability, usability, efficiency, maintability, dan portability yang ditunjukkan pada Tabel I.

TABEL I

KARAKTERISTIK DAN SUB-KARAKTERISTIK ISO 9126 [5]

\begin{tabular}{ll}
\hline \hline Karakteristik & Sub-Karakteristik \\
\hline Functionality & suitability, accuracy, interoperability, security \\
Reliability & maturity, fault tolerance, recoverability \\
Usability & understandability, learnability, operability, attractiveness \\
Efficiency & timebehavior, resource utilization \\
Maintainability & analyzability, changeability, stability \\
Portability & daptability, installability, co-existence, replacability \\
\hline \hline
\end{tabular}

Dalam Web Quality Evaluation Method (WebQEM) [3] mengusulkan beberapa karakteristik untuk melakukan pengujian terhadap aplikasi web. Olsina mengidentifikasikan empat karakteristik dari sisi pengguna yaitu functionality, efficiency, reliability, dan usability. Alasan mengidentifikasi keempat karakteristik tersebut karena dalam bidang akademik orientasi penting adalah pengguna (siswa, guru, dsb). Setiap aspek dapat diukur menggunakan metode pengukuran yang berbeda [6].

\section{B. Jenis Penelitian}

Penelitian ini menggunakan model penelitian dan pengembangan (research and development) yang digunakan untuk menghasilkan produk tertentu dan menguji keefektifan produk tersebut [7]. Model pengembangan yang digunakan adalah model proses waterfall. Model proses waterfall adalah model klasik yang bersifat sistematis, berurutan dalam membangun suatu perangkat lunak [8]. Gambar 1 merupakan tahapan-tahapan dalam model waterfall [9]:

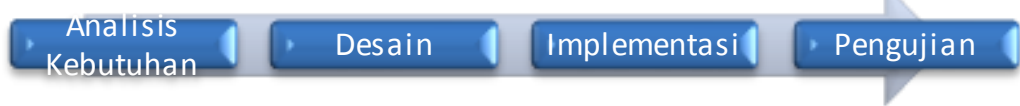

Gambar 1. Model Waterfall

\section{Waktu dan Tempat Penelitian}

Penelitian ini dilakukan pada tanggal 8 November 2013 hingga 14 Maret 2014. Penelitian ini dilakukan di SMK Negeri 2 Depok Sleman.

\section{Subjek Penelitian}

Subjek penelitian dalam penelitian ini adalah siswa dan guru (usability), ahli pemrograman (functionality), dan dokumentasi (efficiency dan reliability).

\section{E. Prosedur}

\section{1) Analisis Kebutuhan}

Pada tahap analisis kebutuhan dilakukan identifikasi kebutuhan apa saja yang diperlukan dalam perancangan sistem informasi akademik. Kemudian dibuat daftar permintaan atau kebutuhan pengguna (user requirement list) yang perlu dikembangkan dalam sistem informasi akademik ini.

2) Desain

Desain yang dibuat dalam penelitian ini adalah desain UML (use case diagram, activity diagram, class diagram, sequence diagram), desain database, dan desain interface.

3) Implementasi

Implementasi dilakukan dengan menggunakan framework Codeigniter dan database MySQL. 


\section{4) Pengujian}

Dalam Web Quality Evaluation Method (WebQEM) [3] mengusulkan beberapa karakteristik untuk melakukan pengujian terhadap aplikasi web. Olsina mengidentifikasikan empat karakteristik yaitu functionality, efficiency, reliability, dan usability. Pengujian yang dilakukan adalah functionality, efficiency, reliability, dan usability seperti yang telah diidentifikasi untuk aplikasi web dalam WebQEM (Web Quality Evaluation Model).

\section{F. Data, Instrumen, dan Teknik Pengumpulan Data}

1) Functionality

Aspek functionality diuji ahli pemrograman (programmer/ developer) dengan menggunakan kuisioner sesuai dengan fungsi pada user requirement list. Sehingga, dapat diketahui fungsi fungsi yang berjalan dan tidak berjalan (error).

\section{2) Efficiency}

Pengujian ini menggunakan alat ukur YSlow yang dikembangkan oleh Yahoo Developer Network dan Page Speed yang dikembangkan oleh Google Developer untuk mengukur performa efisiensi sebuah halaman website. Performa yang akan diukur adalah besarnya bytes data dokumen, jumlah HTTP request, minifikasi, kompresi GZIP, dan score / grade akhir.

3) Reliability

Aspek reliability diuji menggunakan pengujian stress testing. Stress testing adalah salah satu jenis pengujian sistem (system testing). Stress testing menjalankan sebuah sistem dengan sumber daya jumlah, frekuensi atau volume yang abnormal [8]. Pengujian ini dilakukan oleh peneliti dengan menggunakan software Web Application Load, Stress and Performance Testing yang meliputi beberapa parameter pada error report yang ada dalam software tersebut: Failed Session, Failed Hits, dan Failed Pages.

4) Usability

Aspek usability diukur menggunakan kuisioner. Pengujian ini dilakukan dengan menggunakan instrumen Usefulness, Satisfaction, and Ease of use (USE) Questionnaire yang dikembangkan oleh STC Usability and User Experience Community [10]. Kuisioner usability ini menggunakan 5 poin skala Likert positif [11].

\section{G. Teknik Analisis Data}

Data yang didapatkan dari setiap instrumen akan dihitung rata-rata menggunakan rumus (1).

$\bar{x}=\frac{\sum x}{n}$

\section{Dimana:}

$\bar{x}=$ skor rata-rata

$x=$ skor total item

$n=$ jumlah item

Sedangkan untuk menghitung skor persentase kelayakan menggunakan rumus (2).

$$
\text { Kelayakan }(\%)=\frac{\text { Skor yang diobservasi }}{\text { Skor yang diharapkan }} \times 100 \%
$$

Setelah mendapatkan hasil berupa nilai kuantitatif dari perhitungan sebelumnya, kemudian nilai dikonversi menjadi nilai kualitatif berskala 5 dengan skala Likert. Konversi persentase ke pernyataan seperti dalam Tabel II berikut [12]:

TABEL 1

\begin{tabular}{lll}
\multicolumn{2}{c}{ PENYESUAIAN INTERPRETASI LIKERT } \\
\hline \hline No & Persentase & Interpretasi \\
\hline 1 & $0 \%-20 \%$ & Rendah Sekali \\
2 & $21 \%-40 \%$ & Rendah \\
3 & $41 \%-60 \%$ & Cukup Tinggi \\
4 & $61 \%-80 \%$ & Tinggi \\
5 & $81 \%-100 \%$ & Sangat Tinggi \\
\hline \hline
\end{tabular}

\section{1) Functionality}

Pengukuran functionality dilakukan oleh ahli pemrograman (programmer/ developer) dengan rumus (3).

$X=1-\frac{A}{B}$

Dimana:

$X=$ functionality

$A=$ jumlah total fungsi yang tidak valid 
$B=$ jumlah seluruh fungsi

Berdasar rumus (3) tersebut, functionality dikatakan baik jika $X$ mendekati $1(0<=X<=1)$.

2) Efficiency

Pengujian faktor efficiency akan dilakukan menggunakan parameter dasar yang dikemukakan oleh Yahoo Developer Network dan untuk Page Speed menggunakan parameter yang direkomendasikan oleh Google Developer. Setelah mendapat score dari hasil pengujian maka dihitung persentase dengan rumus persentase dan interpretasi sesuai rekomendasi Yahoo Developer Network ditunjukkan pada Tabel III.

TABEL 2

ANALISIS DATA PENGUJIAN EFFICIENCY BERDASARKAN GRADE

\begin{tabular}{lll}
\hline \hline No. & \multicolumn{1}{c}{ Score } & Grade \\
\hline 1. & $90-100$ & $\mathrm{~A}$ \\
2. & $80-89$ & $\mathrm{~B}$ \\
3. & $70-79$ & $\mathrm{C}$ \\
4. & $<69$ & $\mathrm{D}$ \\
\hline \hline
\end{tabular}

Batas waktu untuk menjaga perhatian pengguna dapat menunggu load dari halaman web adalah 10 detik [13]. Sedangkan menurut [14] waktu terbaik untuk load halaman website adalah kurang dari 3 detik, untuk waktu tunggu yang dapat diterima kurang dari 10 detik.

3) Reliability

Berikut adalah rumus untuk menghitung reliability menurut model Nelson [15]:

$R=\frac{n-f}{n}=1-\frac{f}{n}=1-r$

Dimana,

$R=$ Reliability

$f=$ Total failure

$n=$ Total test case (workload unit)

$r=$ Error rate

Menurut Standar Telcordia yang dikutip oleh Asthana, keberhasilan reliabilitas perangkat lunak adalah 95\% atau 0.95 [16].

4) Usability

Pengujian faktor usability diujikan menggunakan kuisioner. Kuisioner akan dibagikan kepada 30 responden sebagai pengguna yang terdiri dari siswa dan guru. Menurut Nielsen untuk penelitian kuantitatif jumlah responden untuk menguji faktor usability minimal 20 orang [17]. Skala yang digunakan dalam pengujian faktor usability menggunakan skala Likert sehingga nanti dapat disimpulkan mengenai kelayakan perangkat lunak dari sisi pengguna.

Perhitungan Alpha Cronbach dihitung menggunakan perangkat lunak SPSS dengan interpretasi nilai reliabilitas Alpha Cronbach ditunjukkan pada Tabel IV [18].

TABEL 3

\begin{tabular}{cll}
\multicolumn{3}{c}{ INTERPRETASI ALPHA CRONBACH } \\
\hline \hline No. & \multicolumn{1}{c}{ Nilai R } & \multicolumn{1}{c}{ Interpretasi } \\
\hline 1. & $\mathrm{R}>0.9$ & Excellent \\
2. & $0.9>\mathrm{R}>0.8$ & Good \\
3. & $0.8>\mathrm{R}>0.7$ & Acceptable \\
4. & $0.7>\mathrm{R}>0.6$ & Questionable \\
5. & $0.6>\mathrm{R}>0.5$ & Poor \\
6. & $\mathrm{R}<5$ & Unacceptable \\
\hline \hline
\end{tabular}

III.HASIL

\section{A. Analisis Kebutuhan}

Beberapa fungsi minimal yang dibutuhkan antara lain:

1) Guru dan siswa didaftarkan oleh admin.

2) Guru dapat menambah data nilai akademik siswa sesuai mata pelajaran yang diampu pada semester tertentu.

3) Guru yang juga sebagai wali kelas dapat menambah nilai akademik siswa sesuai mata pelajaran yang diampu pada tahun ajaran dan semester tertentu dan dapat memasukkan presensi serta ekstrakurikuler yang diikuti siswa.

4) Guru dan siswa dapat melihat profil masing-masing.

5) Guru dan siswa dapat mengubah profil masing-masing.

6) Admin dapat menambah, mengubah, menghapus, mengunduh, mengunggah, mencari, dan mencetak data. 


\section{B. Desain}

Desain yang dilakukan adalah:

1) Use Case Diagram

Use case diagram sistem secara keseluruhan ditunjukkan pada Gambar 2.

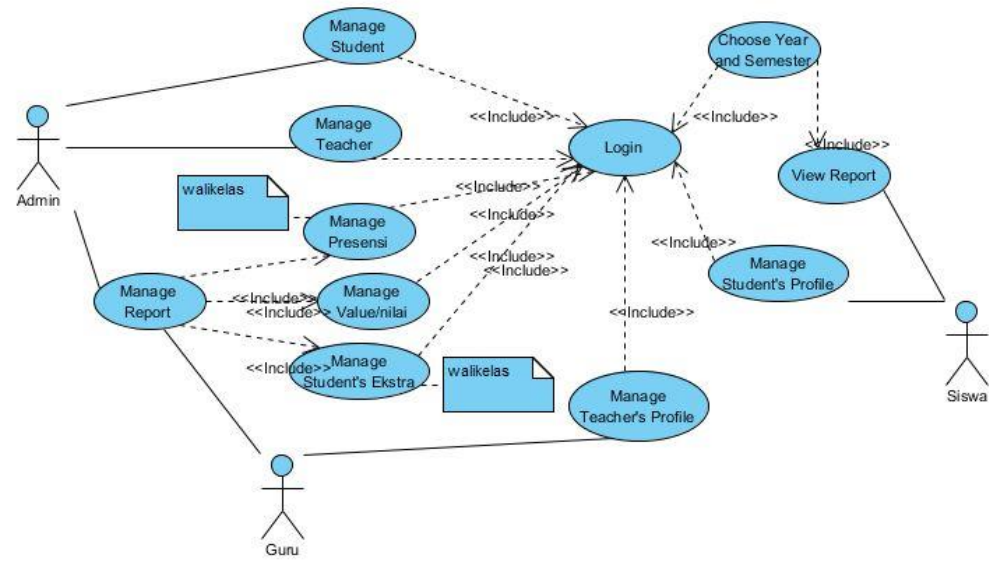

Gambar 2. Use Case Diagram Sistem

Use case diagram menggambarkan semua aktor dengan skenario masing-masing.

2) Desain Basis Data

Perancangan basis data untuk sistem informasi akademik ditunjukkan pada Gambar 3.

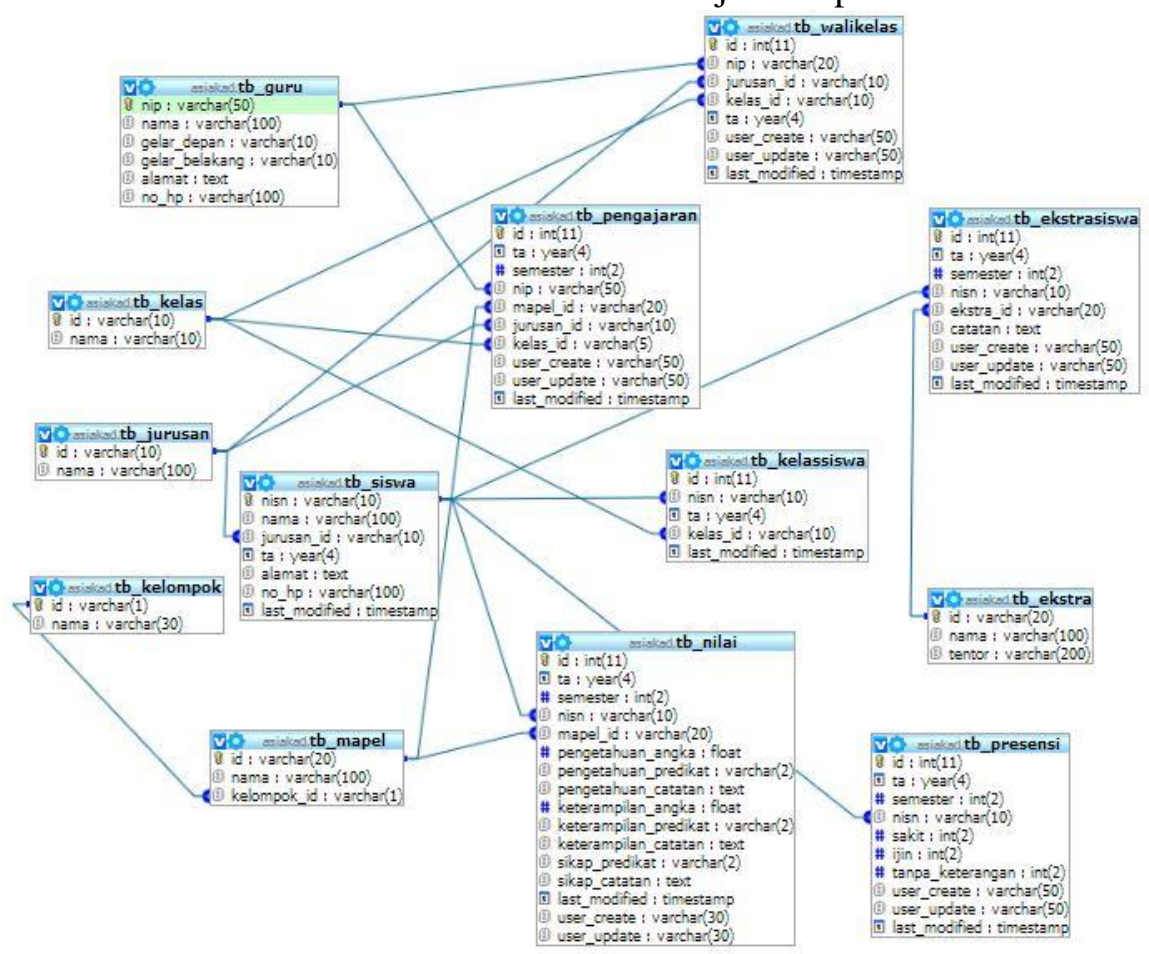

C. Implementasi

Gambar 3. Perancangan Basis Data

Implementasi fungsi dilakukan menggunakan framework Codeigniter. Implementasi fungsi untuk sistem informasi akademik ditunjukkan pada Gambar 4.

\section{PEMBAhASAN}

Hasil pengujian dari sistem informasi akademik adalah sebagai berikut:

1) Functionality

$$
X=1-\frac{A}{B}=1-\frac{0}{166}=1
$$

Berdasarkan hasil perhitungan pengujian functionality, didapatkan nilai functionality sebesar 1. Dari skor tingkat functionality tersebut maka kualitas perangkat lunak dari sisi functionality dapat dikatakan 'Baik' sesuai interpretasi dari ISO 9126 yaitu nilai yang baik adalah nilai yang mendekati 1. Dari hasil tersebut maka Sistem 
Informasi Akademik SMK Negeri 2 Depok Sleman layak digunakan untuk mendukung pengelolaan akademik siswa karena sistem tersebut telah lolos dalam uji functionality.

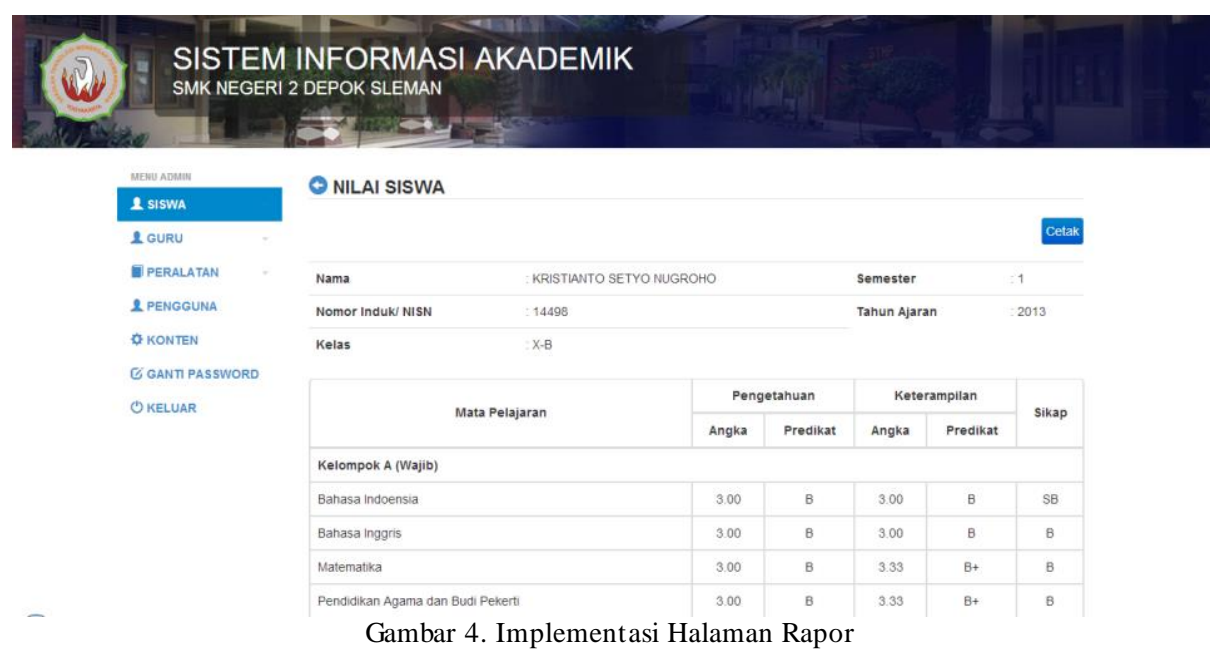

2) Efficiency

Gambar 5 merupakan salah satu capture hasil pengujian efficiency menggunakan Yslow.

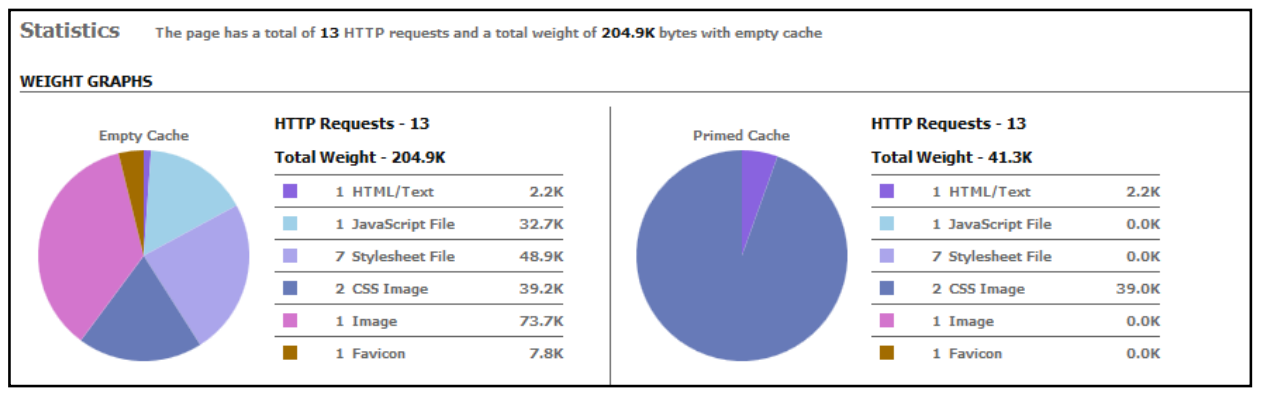

Gambar 5. Statistik Pengujian Efficiency Halaman Login

Berdasarkan analisis dan perhitungan pengujian efficiency maka diperoleh persentase $96 \%$ (Grade A) dengan alat ukut YSlow dan 94\% (Grade A) dengan alat ukur Page Speed. Pengujian menggunakan alat ukur YSlow maupun Page Speed menunjukkan hasil yang sama yaitu mendapatkan Grade A, sehingga dapat dikatakan perangkat lunak memiliki nilai efficiency tinggi. Dari score yang didapat maka kualitas perangkat lunak yang dikembangkan dari sisi efficiency mendapatkan 'Grade A' jika disesuaikan dengan aturan yang direkomendasikan oleh Yahoo Developer Network.

Berdasarkan analisis dan perhitungan maka diperoleh rata-rata waktu tunggu (load time) untuk tiap halaman web, dimana dengan kecepatan modem $37.1 \mathrm{kB} / \mathrm{s}$ rata-ratanya adalah 3.33 detik dan dengan kecepatan modem $67.72 \mathrm{kB} / \mathrm{s}$ rata-ratanya adalah 1.043 detik. Berdasarkan data tersebut maka waktu tunggu dapat dikatakan 'Diterima' dengan menggunakan interpretasi yang direkomendasikan oleh Microsoft maupun Nielsen.

TABEL 4

Hasil PenguJian Stress Testing

\begin{tabular}{lrrrrrr}
\hline \hline Profile & $\begin{array}{c}\text { Successful } \\
\text { sessions }\end{array}$ & $\begin{array}{c}\text { Failed } \\
\text { sessions }\end{array}$ & $\begin{array}{c}\text { Successful } \\
\text { pages }\end{array}$ & $\begin{array}{c}\text { Failed } \\
\text { pages }\end{array}$ & $\begin{array}{c}\text { Successful } \\
\text { hits }\end{array}$ & $\begin{array}{c}\text { Failed } \\
\text { hits }\end{array}$ \\
\hline Siswa & 308 & 4 & 4066 & 4 & 8841 & 13 \\
Guru & 0 & 54 & 638 & 0 & 1433 & 5 \\
Total & 308 & 58 & 4704 & 4 & 10274 & 18 \\
\hline \hline
\end{tabular}

\section{3) Reliability}

Pengujian reliability dilakukan menggunakan perangkat lunak WAPT versi 8.1. Pengujian tersebut menggunakan 20 user simultan dengan waktu percobaan selama 60 menit. Hasil yang didapat adalah total test case yang diakses adalah 15289 dan total kegagalan yang terdeteksi yaitu 80 kegagalan. Hasil menunjukkan bahwa didapatkan nilai reliability adalah 99,5\% sehingga dapat dikatakan 'Memenuhi' kriteria standar reliability yang ditetapkan dalam standar Telcordia. Dari hasil tersebut maka Sistem Informasi Akademik SMK Negeri 2 Depok Sleman layak digunakan untuk mendukung pengelolaan akademik siswa karena sistem tersebut telah lolos dalam uji reliability.

Tabel V merupakan hasil pengujian Stress Testing pada sistem informasi akademik yang dikembangkan. 


\section{4) Usability}

Berdasarkan perhitungan tersebut maka diperoleh persentase $74,33 \%$ dari pengujian usability. Dari skor tersebut, sesuai dengan interpretasi skala Likert, maka dapat dikatakan perangkat lunak ini "Tinggi" dari sisi usability. Dari hasil tersebut maka Sistem Informasi Akademik SMK Negeri 2 Depok Sleman layak digunakan untuk mendukung pengelolaan akademik siswa karena sistem tersebut telah lolos dalam uji usability. Instrumen yang digunakan yaitu USE Questionnaire juga dapat dikatakan 'Baik' karena memiliki nilai Alpha Cronbach 0.872 .

\section{A. Simpulan}

\section{SIMPULAN DAN SARAN}

Berdasarkan hasil penelitian dan pembahasan yang telah dilakukan, dapat disimpulkan bahwa: (1) Sistem Informasi Akademik SMK Negeri 2 Depok Sleman dikembangkan menggunakan framework Codeigniter dan berdasarkan model pengembangan Waterfall yaitu, 1) Analisis kebutuhan; 2) Desain; 3) Implementasi; dan 4) Pengujian. Sistem ini menerapkan Kurikulum 2013 dengan fitur: manajemen admin, manajemen guru, manajemen wali kelas, dan siswa (2) Kualitas perangkat lunak diuji melalui beberapa aspek yaitu functionality, efficiency, reliability, dan usability. Dalam aspek functionality, sistem ini mendapatkan nilai functionality adalah 1 (baik). Dalam aspek efficiency, sistem ini memperoleh tingkat kelayakan sebesar 94\% dengan YSlow dan 96\% dengan Page Speed (Grade A) serta waktu tunggu sebesar 3,33 detik (Diterima). Dalam aspek reliability, sistem ini mendapatkan nilai reliability $99,5 \%$ (memenuhi). Dalam aspek usability, sistem ini memperoleh persentase 74,33\% (Tinggi) dan nilai Alpha Cronbach sebesar 0,872 (baik).

\section{B. Saran}

Berdasarkan keterbatasan produk maupun waktu, maka penulis menyarankan untuk pengembangan penelitian di masa yang akan datang sebagai berikut: (1) Pengembangan perangkat lunak jika kurikulum berubah. (2) Autentifikasi pengguna yang lebih beragam, dan (3) Teknik pengujian yang lebih beragam dan mengungkap kualitas perangkat lunak khususnya untuk sistem informasi akademik.

[1] Danim, S., Otonomi manajemen sekolah, Alfabeta, Bandung, 2010

[2] Sallis, E., Total quality management in education”, Stylus Publishing Inc., US, 2005.

[3] Olsina, L., Godoy, D., \& Lafuente, G. J., Specifying quality characteristics and attributes for websites", 2003.

[4] ISO/ IEC, Software engineering: product quality - part 2 - external metric, Canada: International technical report, 2001.

[5] ISO/ IEC, International standard ISO/IEC 9126, Switzerland: Joint Technical Committee, 1991.

[6] Martin, M., \& Olsina,L., "Towards an ontology for software metrics and indicators as the foundation for a cataloging web system",. Proceedings of the First Latin American Web Congress, America: IEEE Computer Society, 2003.

[7] Sugiyono, Metode Penelitian Kuantitatif, Kualitatif, R\&D, Bandung: Alfabeta, 2010.

[8] Pressman, R. S., Software engineering a practitioner's approach, New York: McGraw-Hill, 2010.

[9] Pressman, R. S., Software engineering: a practiotioner's approach, New York: Thomas Casson, 2001.

[10] Lund, A. M., “Measuring Usability with the USE Questionnaire”, 2014, [Online]. Tersedia: http://www.stcsig.org/usability/newsletter/0110 _measuring_with_use.html

[11] Muderedzwa, M., \& Nyakwende, E., “The Effectiveness of Online Employment Background Screening Systems”, African Journal of Business Management Vol. 4(17), hal. 3599, Mmabatho, 2010.

[12] Riduwan, \& Akdon, "Rumus dan Data dalam Analisis Statistika", Bandung: Alfabeta, 2008.

[13] Nielsen, J., “Website Response Times”, Nielsen Norman Group, 2014. [Online]. Tersedia: http://www.nngroup.com/articles/website-response-times/

[14] Meier, J. D., Farre, C., Bansode, P., Barber, S., \& Rea, D., “Quantifying End-User Response Time Goals”, Microsoft Developer Network. [Online]. Tersedia: http://msdn.microsoft.com/en-us/library/bb924365.aspx

[15] Tian, J., "Evaluating Web Soft ware Reliability Based on Workload and Failure Data Extracted from Server Logs", IEEE TRANSACT IONS ON SOFT WARE ENGINEERING, hal. 754, 2004.

[16] Asthana, A., \& Olivieri, J., "Quantifying Software Reliability and Readiness. Communications Quality and Reliability", IEEE International W orkshop Technical Committee on Westford: IEEE, 2009.

[17] Nielsen, J., "How Many Test Users in a Usability Studi”, Nielsen Norman Group, 2014. [Online]. Tersedia: http://www.nngroup.com/articles/howmany-test-users/

[18] Gliem, J. A., \& Gliem, R. R., “Calculating, Interpreting, and Reporting Cronbach's Alpha Reliability Coefficient for Likert-Type Scales”, Midwest Research to Practice Conference in Adult, Continuing, and Community Education, hal. 82, 2003. 